IPSI Revista de Investigación en Psicología

1998, Vol. 1, No 1. pp. 89.117

\title{
AUTOESTIMA Y VALORES EN LA CALIDAD Y LA EXCELENCIA
}

\author{
Alejandro Loli Pineda * \\ Ernestina López Vega **
}

\begin{abstract}
El artículo analiza la calidad humana como factor principal de desarrollo de las organizaciones. Sostiene que la calidad humana, en gran medida, es producto $\sim$ la formación y desarrollo de la autoestima y que ésta constituye el sustento de los valores que son los que se encargan de regular la conducta humana. Así la llave de la calidad y el éxito del hombre se encuentra esencialmente en la autoestima (alta) que conducirá a establecer interacciones sociales positivas, entre ellas su desempeño en el trabajo, creando condiciones de retroalimentación permanente. De este modo, la formación de la autoestima y los valores se convierten en un reto para las familia." para los lideres organizacionales y principalmente gubernamentales.
\end{abstract}

Palabras clave: Autoestima, valores, calidad, excelencia, organización

The article analyzes the quality human as principal development factor of the organizations. Support that the human quality, in great measure, it is product of the training and development of the self-esteem and that this constitutes the sustenance of the values that they are those which are entrusted with regulating the human conduct. Thus the key of the quality and the success of the man is found substantially in the self-esteem (high) that will lead to establish positive social interactions, between them your performance in the work, creating permanent feedback conditions. Of this manner, the training of the self-esteem and the values are converted into a challenge for the families, for the organization leaders and mainly governmental.

Key words: Self esteem, values, quality, excellence, organization.

* Dr. en Psicología, Mg. en Ciencias de la Cooperación y docente principal de la UNMSM

** Dra. en Psicología y docente principal de la UNMSM.

E-mail: d208821@unmsms.edu.pe

El presente artículo es un adelanto de una investigación más amplia que será publicada posteriormente. 
En los últimos años, un cambio total en la política de gobierno permite abrir las fronteras del país a la tecnología, a la globalización de la economía y al libre mercado, revalorando al cliente del servicio o al consumidor del producto que exige cada vez valores positivos (honradez, confianza, cortesía, respeto, comodidad, responsabilidad, calidad, excelencia), precio justo y productos de calidad.

Las organizaciones en nuestro país comienzan entonces a interesarse por este nuevo orden de cosas. Quienes han logrado involucrarse en este reto, saben que el secreto está en la calidad humana y vienen trabajando para formar, cambiar o reconstruir los valores como uno de los pilares fundamentales de la calidad. Sin embargo, si bien la educación del adulto no está del todo errada, el trabajo básico debe estar dirigido a construir la autoestima de las nuevas generaciones, porque los resultados, en la situación actual será muy frágil temporal e inconsistente a las necesidades del momento. Hacer lo correcto implica, por tanto, trabajar a nivel de familia con los niños, especialmente durante su primera infancia; en segunda instancia, con los jóvenes y adultos: como parte de un proceso de transición hacia un cambio definitivo.

Visto de este modo la calidad y la excelencia de los productos y servicios se encuentran relacionados con la naturaleza humana, y más precisamente con la autoestima y los valores, dependiendo en lo fundamental de ella; por que la tecnología como las demás variables son elaboradas o construidas, manejadas y controladas por la mano del hombre. Es él quien crea y usa la tecnología, implementa los cambios y logra estándares aceptables de calidad a sus productos o servicios. Es él quien mantiene una infraestructura presentable, higiénica, ordenada, clasificada y saludable; es él quien está en el "momento de la verdad" frente al cliente, convirtiéndose en su mejor promotor y publicista en el mercado, por tanto, y su representante e imagen ante la sociedad.

Es así como, después de revisar y analizar algunas fuentes $\mathrm{y}$ experiencias, se ha logrado sistematizar la información sobre la autoestima y su trascendencia en las organizaciones y en la sociedad.

\section{LA AUTOESTIMA}

La autoestima es un fenómeno psíquico inherente al ser humano y forma parte de él desde que el hombre es hombre. Sin embargo fue 
Aristóteles quien usó el término para referirse al "amor a sí mismo" y fue William James que estudió el desdoblamiento del "yo", en "yo-conocedor" y "yo-conocido", involucrando en algún grado la autoestima, dando nacimiento a un fenómeno psíquico que más tarde sería la clave del éxito personal. A mitad del presente siglo, con la aparición de la psicología humanista, la autoestima adquiere relevancia predominante gracias a la contribución de Carl Rogers. Precisamente la teoría psicoterapéutica de Rogers se centra en la persona sobre la base de la auto estima Encuentra que la raíz de los problemas de muchas personas es que se desprecian y se consideran seres sin valor e indignos de ser amados. Goethe decía, " ... La peor desgracia que le puede suceder a un hombre es pensar mal de sí mismo".

\subsection{Definición}

Existen muchos estudiosos que tratan de definir la autoestima, probablemente la intención sea la de comprender mejor el contenido del término. Aquí tenemos algunas de ellas:

- " ...constituye el núcleo básico de la personalidad ...." (Rogers, 1969)

- " ...es la manera en que Ud. se percibe así mismo ...." (Crisp Publications, enc., 1992)

- "...es una actitud hacia uno mismo ... es la disposición permanente según la cual nos enfrentamos con nosotros mismos ... " (Alcántara, 1993)

- $\quad$ "...es un sentimiento que se expresa siempre con hechos ... " (Clemes y Bean, 1993)

- $\quad$ "...Buena parte del concepto que de sí mismo se forma el niño es producto de la idea que tiene él de como lo juzgamos ... " (Calero, J 996)

- $\quad$ "...es el sistema de repertorios verbo emocionales que aquel ha adquirido y tiene, (. .. ) sobre su propio comportamiento en general y las respuestas efectivas que puede emitir en situaciones impersonales e interpersonales ... " (Montgomery, 1997)

- $\quad$ "...Si una persona se conoce y está consciente de sus cambios, crea su propia escala de valores y desarrolla sus capacidades; y si se acepta y respeta, tendrá autoestima ... " (M. Rodríguez, s/f.)

Todas estas definiciones llevan a inferir, que existen contenidos cognitivos, afectivos y volitivos. Es, decir, conocimiento, valoración afectiva y manejo racional del comportamiento. Sin embargo; existen autores que le atribuyen la presencia de otros elementos además del conocimiento previo de sus necesidades y habilidades para actuar $\mathrm{y}$ 
sentir (autoconocimiento); sin duda la que dichos elementos contribuirán también, de alguna manera, a un mejor conocimiento de sí mismo. Es el caso del significado que el sujeto debe tener acerca de sí mismo, de su relación con los demás ante situaciones nuevas, ante la vida y ante la aceptación que tiene para los demás (autoconcepto); o la necesidad de poner en juego su capacidad interna para evaluar las cosas buenas o malas, según las cuales será posible sentirse bien o mal, enriquecerse o no, crecer o decrecer (autoevaluación); más aún, admitirse y reconocerse tal cual es para transformarse si es preciso (autoaceptación); aunque no será posible el equilibrio si en la persona no hay respeto por la satisfacción de sus propias necesidades y valores, por sus sentimientos y emociones para sentirse orgulloso de sí mismo (autorrespeto).

De esta manera, las personas que no se conocen, no tienen un buen concepto de sí misma, no pueden crear su propia escala de valores y desarrollar sus propias capacidades, no se aceptan ni se respetan; luego, no tienen autoestima. Así, los valores se habrían formado durante el proceso de desarrollo sin ninguna base que lo sostenga, vale decir, que los valores positivos dependen en gran medida de algún grado de autoestima forjada

\subsection{Procedencia de la Autoestima}

La autoestima tiene su origen en el proceso de desarrollo del ser humano y en los factores de su entorno que ejercerán influencia sobre él. Según Sigmund Freud tiene sus orígenes en la etapa oral (primer día de nacido a 18 meses) donde surge la crisis de transición al pasar de la "confianza habitual" a la "desconfianza", es el momento donde el niño recibe todo lo que le dan y no tiene capacidad para dar. Erik Erikson (1950) considera que la autoestima tiene sus orígenes en la etapa sensorio-oral (1 a 2 años), o de la "confianza" y "desconfianza", dependiendo de la estabilidad y continuidad que los padres ofrecen al infante. Vandenbergh (1963), afirma que la confianza se desarrolla en base a comprensión y amor (en A. Loli, 1989). Significa que al inclinarse hacia un desarrollo de plena confianza se va construyendo la fe, la esperanza, la aceptación de sí mismo y de los demás; así, el niño se percibe importante y valioso, afianzando su autoestima. 
Los filósofos del siglo XIX decían que "... un hombre es lo que desea, lo que ama ..." (Allport, 1968); sin embargo, nunca alcanzamos plenamente lo que deseamos, pero ésta es una fuerza que une nuestras energías, de modo que vale la pena perseguir.

La autoestima es un objetivo que todos debemos procurar en el proceso de desarrollo del niño, es una fuerza unificadora de ideas, creencias y percepciones que permite tener conocimiento y opinión de sí mismo, dando origen, crecimiento y fortalecimiento de la autoestima en cada persona Por ejemplo, cuando un niño es invitado u obligado a retirarse para que los adultos discutan asuntos supuestamente "serios", el niño capta el mensaje atribuyéndose un concepto de incompetencia, incapacidad y poco importante como ser humano. Ocurre lo contrario si el niño participa en el tratamiento de problemas domésticos y otros, junto con los adultos, dentro de las limitaciones naturales de su edad.

\section{a) El mensaje en el desarrollo de la autoestima}

En el lenguaje de Erik Erikson (1950), los mensajes que reciben las personas o se transmiten al "niño" a temprana edad en la familia, luego en el barrio y la escuela; al "adolescente" en el colegio y la Universidad: al "adulto" o al hombre "maduro" en el trabajo, contribuyen a consolidar o desestabilizar la autoestima Esto no tiene tanto que ver con el tipo ni con el medio de comunicación, son los componentes que acompañan a ellos que muchas veces comunica mejor el mensaje; es el tono de voz, es la energía con que se expresa, son los niveles de organización o desorganización de dichas expresiones los que dicen más allá de las palabras; son los movimientos corporales, los gestos, entre otros lo que muchas veces transmiten mejor lo que se dice. De manera que el cuidado que se debe tener al transmitir un mensaje en toda interacción social, tomando en cuenta los efectos que puede causar, especialmente en los niños y adolescentes, es una expresión de madurez de todo ser humano.

\section{b) El tú y la conciencia de sí}

M. Rodríguez y colaboradores en su obra Cómo Desarrollar la Autoestima, nos dicen que " ... lo que no conozco no puedo amarlo... ", esta 


\section{Alejandro Loli / Ernestina López}

expresión hace pensar en la necesidad previa de conocerse así mismo para amarse, así como resulta imposible comprometerse con amor en algo que no ,conoce a, plenitud. Precisamente este conocimiento se logra al descubrir el "tú" (expresiones como mamá, papá indican tal conocimiento) y que "yo" soy una persona distinta a otra. Luego cuando las personas experimentan, reciben o le imponen situaciones diversas con las que van logrando conocimiento pleno de sí mismo, un concepto de sí, una imagen, se aceptan y se respetan consolidando así su autoestima

Dirigir su vida para toda persona es una forma de experimentar el desarrollo de sus facultades físicas, mentales y sociales. Es ponerse en prueba frente al mundo. El hombre es el único ser de la creación que tiene conciencia de sí, sentimientos y emociones, e inteligencia, entre otras múltiples bondades. Es la conciencia que le permite darse cuenta de su existencia en el pasado, en el presente y en el futuro, es decir, su "yo"; son los sentimientos y las emociones los que permiten conocerse así mismo (ello), es la fuerza moral la que conduce y controla esos actos y sentimientos de acuerdo a las circunstancias (super yo), y es la inteligencia la que intenta comprender o explicar.

Así, el hombre es capaz de aprehender y recordar, o mantener dichas experiencias positivas o negativas en el inconsciente y reaccionar emocionalmente frente a estímulos que exaltan ése depósito de experiencias. Cuando son recuerdos positivos la persona se enorgullece, su autoestima crece y es capaz de realizaciones creativas, innovadoras, llega a ser lo que quiere ser. De allí que se diga que la "autoestima es la clave del éxito". Como decían Elkins, Rogers, Maslow, Bettelheim y otros, la "autoestima es una parte fundamental para que el hombre alcance la plenitud y autorrealización en la salud física y mental, productividad y creatividad; es decir, en la plena expresión de sí mismo" (en M. Rodríguez y col.).

Si las experiencias que se mantienen en el inconsciente son negativas, la estimulación posterior de las mismas hacen reaccionar también negativamente. Por ejemplo, cuando dicen "yo soy como soy y nadie me va cambiar", "odio mi proceder cuando me equivoco al hacer algo", son expresiones comunes en este tipo de personas, generalmente estas personas son intolerantes a la frustración, raras veces toman iniciativa, son inseguras, incapaces de tomar decisiones, y si lo hacen corren el 
riesgo de equivocarse. Erik Erikson, en una concepción moderna del psicoanálisis plantea que todo ser humano es capaz de cambiar en el curso de su vida; ese cambio se logra poniendo en juego otras facultades que no son precisamente las emotivas sino las fuerzas morales y sobre todo la inteligencia.

Todo ser humano al hacer conciencia de sus defectos, dominados por los sentimientos y las emociones en su interacción social, recurre a su "super yo", donde se depositan las fuerzas morales y otros valores para ubicar e implantar opciones positivas en lugar de mantener sentimientos negativos; es decir, hacer cosas que le hagan sentir bien, auténtico y natural. Hay un dicho popular en el Perú que reza: "entre el odio y el amor hay sólo un paso". Ello explica la flexibilidad de los sentimientos humanos frente al manejo racional de los acontecimientos.

\section{LOS VALORES}

Todo ser humano desde muy temprana edad alcanza distinguir lo bueno de lo malo; es él y ningún otro ser vivo, capaz de hacer las cosas que quiere hacer, hacer lo que otros quieren que haga y decidir por lo más conveniente a sus intereses. Es decir, ser un próspero hombre de negocios, un feliz padre de familia, un gran amigo del barrio, un hijo maravilloso y un esposo leal y honesto; o ser un despojo de la naturaleza humana que odia haber nacido, con una vida sin sentido y un horizonte sin rumbo; o sea, un mediocre en todo orden de cosas.

Y ¿cuál es la diferencia?, es la calidad de vida que lleva cada quien lo que los hace diferente. Seguramente las personas que tienen una alta calidad de vida son aquellas que se aman a sí mismas y consecuentemente a las demás, perciben el mundo de una manera distinta, valoran su existencia, y todos sus actos se movilizan en tomo de grandes valores, tales como la educación, la verdad, el bien común, la solidaridad, la reciprocidad, etc. Es decir, toda persona que tiene una autoestima positiva es capaz de valorar su entorno en su real dimensión y procura esforzando para sacar la máxima ventaja a las oportunidades que se le presentan a fin de crecer y dejar crecer. Todo lo contrario ocurrirá en personas que tiene una baja calidad de vida, ésta será reflejo de su baja autoestima. 
De manera que, la infinidad de valores que existen alrededor de toda persona, está, presente a la voluntad y decisión de, quien desee tomarlo, como parte de sí. De allí que los "... valores buscados y perseguidos por los individuos y por la empresa, funcionen como motivaciones; y están presentes en cada una de las opciones que tomamos..." diariamente (M. Rodríguez, 1993).

\subsection{Definición}

Existe un número bastante alto de definiciones sobre valores. Presentamos algunas de ellas para tener una idea de la importancia que va alcanzando en los últimos tiempos.

- " ... expresa un sistema de creencias al que suscribe un individuo, un grupo o una organización; refleja una manera particular de encarar diferentes aspectos de la realidad y dicha concepción de la realidad es consecuencia de una elección consciente o inconsciente entre diversas posibilidades .. " (Tannenbaum, 1986)

- " .. conjunto de ideales, principios y estimaciones que las personas ponen en práctica en la relación con sus semejantes ... " (Morillo, s/f)

- "... conceptos del individuo en cuanto a lo correcto, lo bueno o lo deseable .. " (Robbins, 1994)

- $\quad$ "... conjunto de creencias acerca de lo que es verdadero o falso, importante o no importante, que se conservan y apoyan conscientemente .. " (Chiavenato, 1995)

- " ... concepción de lo que es deseable ... una idea que tiene un individuo y que con frecuencia comparte con sus amigos y relaciones, que influyen en su elección sobre qué hacer y cómo hacerlo, definiendo lo que es valioso, atractivo o adecuado". (Caplow,1971)

- $\quad$ ".... son incrementales ... se generan por sí mismos, pues se crean en el interior de los individuos y los grupos a consecuencia de sus actitudes y estilos de vida ... ". (Davis / J. Newstrom,1993)

- $\quad$ ".... son supuestos positivos sobre el potencial y deseo de crecimiento entre los empleados ... ". (Davis / J. Newstrom, 1993)

- $\quad$ "... esa cualidad de un objeto determinado que lo hace de interés para el individuo o para el grupo ... ". (Ismodes. 1970)

Existen muchas otras definiciones, pero como se puede ver, de una u otra forma, objetiva o subjetiva, encontramos que la mayoría de los conceptos tienen un contenido esencialmente emotivo; ciertamente, las definiciones subjetivas poseen mayor carga afectiva, pero eso no las 
excluye -a los conceptos objetivos- el componente que los caracteriza a ambos. Como dice Tannenbaum (1986), al tener un fuerte componente emocional, "el valor tiene el efecto de condicionar en buena medida las actitudes y conductas del individuo o del grupo en cuestión".

Parece claro que, el valor no conduce a una acción inmediata del individuo, sino condiciona a cómo actuar frente a situaciones reales de la vida, pero sí estimula la visión hacia el futuro, que le permite actuar como fuerza motivadora que lleva a trazar proyectos de vida, metas a alcanzar y un mejor criterio de actuación. Luego, por definición, los valores no son directamente observables, son amplios, y actúan como orientadores de la conducta del hombre en la sociedad. Aún en el más extremo objetivismo, encontramos, antes de la acción, un proceso de percepción que la hace subjetiva al valor del objeto. Por ejemplo, el valor que puede tener el agua es distinto para aquél que se encuentra sediento y no encuentra dicho líquido para calmar su sed, que para aquél otro que tiene a la mano para hacer uso de él cuando lo necesite. Igualmente, será diferente el valor que puede tener una muñeca de trapo, deteriorado por el paso del tiempo (obviamente de poco valor económico), para una persona que recibió como regalo de su madre ya fallecida y que fue uno de los pocos juguetes que lo acompañó toda su infancia; que para aquella otra persona que tuvo muchas muñecas y regalos en su vida.

\subsection{Procedencia de los Valores}

S. Freud nos decía que el "ego" o "yo" es parte de la estructura psíquica que representa la conciencia y que permite la interacción social de una persona con otra o con las demás, es decir es el que relaciona a la persona con el mundo exterior. El "ello" es la parte de esa estructura que representa al subconsciente y que se expresa en la forma de impulso. Bela Szekely (1963), decía " ... es la parte animal del hombre ... ". Y el "super ego" o "super yo", es el representante de la sociedad, surge en la primera fase de la evolución del ser humano (entré los 18 meses y 24 meses), donde se le transmite las primeras reglas de la convivencia humana. El super yo comienza con la dominación de los esfínteres, y con esto el niño empieza a transformarse en un ser moral, cuya 
conciencia interna controlador del ello experimenta lo que puede hacer y lo que no debe hacer, Asi nace uno de los primeros valores en la vida del hombre, convirtiéndose el super yo en el lugar donde se ubican y permanecen los valores, dispuestos a los requerimientos del yo en su interacción con el mundo.

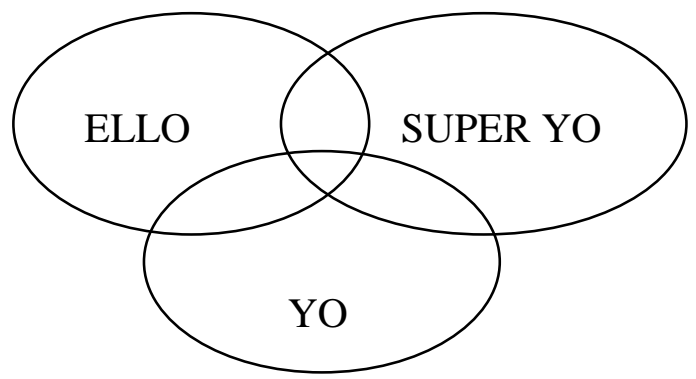

FIGURA 1 Estructura Psíquica : Según la Escuela Freudiana, a medida que un círculo crece e invade al otro hay mayor desarrollo de ese segmento de la Estructura y, por tanto, mayor influencia o dominio en la vida de relación

En términos de J. Piaget (1970), los primeros sentimientos morales surgen del respeto unilateral del niño hacia los padres o el adulto; respeto que provoca la "formación de una moral de obediencia ... " a lo que llama también "sentimientos morales intuitivos", y que van acompañados de regulaciones de intereses y valores relacionados al pensamiento intuitivo.

De este modo o de otro empieza la educación por experiencias propias, por experiencias transmitidas o por intervenciones autoritarias; de manera que, surge la aceptación o rechazo de un hecho o una situación en armonía con los mandatos de la conciencia, dándose el compromiso con la sociedad.

Por consiguiente, hay una interdependencia entre el yo, el ello, el super yo en relación con la consciencia Ciertamente, todos ellos tienen un rol específico que cumplir, pero es el super yo en última instancia el que gobierna la vida del ser humano civilizado. Por que se puede cometer un delito (robo, asalto, asesinato, etc.) o hechos más simples como hablar mal del compañero de trabajo, ser desleal a los hijos, a la esposa o a los amigos causando daño a la integridad física y moral y ser consciente de ello, sin que se pueda evitar; sin embargo, el super yo crecido con suficientes 
fuerzas morales y otros valores de convivencia y de desarrollo social -como la inteligencia- estaría en condiciones no sólo de evitar tremendo daño a la sociedad sino de no permitir la ocurrencia de hechos vetados por ella Así la conciencia no es sino "testigo" de la ocurrencia o no de un hecho y que le permite a la persona darse cuenta de sus actos.

Cuando ocurren casos tales como actuar mal hacia los demás, se estaría frente a un desarrollo mayor del ello, sin sentimientos de culpa alguna, decrecimiento del super yo y un yo debilitado para encara con aplomo y seguridad al mundo. En otros términos, baja autoestima y escasos valores de dicho ser vivo para enfrentarse a un mundo de normas implícitas y explicitas para la convivencia entre humanos.

\section{RELACION ENTRE AUTOESTIMA Y VALORES}

La naturaleza de la autoestima y los valores nos permite establecer que éstos tienen su origen en el proceso de formación y consolidación de la estructura psíquica: "yo", "super yo" y "ello". Es decir, mientras el "ello" aparece como parte natural del ser humano y que viene con él, el "yo" y el "super yo" aparecen en las primeras interacciones del sujeto con el mundo exterior. Así, mientras la autoestima aparece en la interacción entre el "ello" y el "yo" que intentan interactuar con el exterior, los valores surgen con la aparición de las primeras reglas de convivencia social humana que dan pie a la formación del "super yo" (ver cuadro 1).

Teóricamente se espera que entre los tres segmentos de la estructura psíquica debe existir equilibrio; sin embargo, es difícil que eso ocurra, dependiendo de las circunstancias e influencias del ambiente que rodea en el momento y las interacciones que suceden en la vida del ser humano, el equilibrio se rompe; aunque la preocupación por lograr el equilibrio en el hombre es permanente en el curso de su vida. Este desbalance hace que las personas actúen con predominancia de los impulsos o de las fuerzas morales y tal vez de un "ego" exagerado. Por ejemplo: un trabajador que sin motivo suficiente agrede física o verbalmente a su compañero, estaría actuando, con predominio del "ello" otro trabajador en cambio suele buscar una solución pacífica, dialogada, con respeto a; la persona y a sus derechos, caso en el "que estaría actuando con predominio del "super yo"; un supervisor que no respeta los sentimientos humanos ni la razón para actuar, 
con tal de quedar bien con su inmediato Superior, en cambio, estaría actuando con predominio de un "yo" narcisista y tal vez psicopática.

\section{CUADRO 1. INTERRELACION AUTOESTIMA VALORES}

\begin{tabular}{|c|c|}
\hline AUTOESTIMA & VALORES \\
\hline $\begin{array}{ll}\text { - } & \text { Proceso de formación de } \\
\text { estructura psíquica. } \\
\text { - } & \text { Primer día a } 18 \text { meses o } 2 \text { años } \\
\text { - } & \text { Etapa oral o sensorio - oral. } \\
\text { - } & \text { Crisis de transición: } \\
& \text { Confianza - Desconfianza. } \\
\text { - } & \text { Se construye el "yo" sobre la } \\
\text { base del "ello": la confianza, la } \\
\text { fe, la aceptación de si mismo y } \\
\text { de los demás. } \\
\text { Autoconocimiento con el que } \\
\text { se inicia la autoestima. } \\
\text { Educación: Consolida } \\
\text { aut.oestima }\end{array}$ & $\begin{array}{ll}\text { - } & \text { Proceso de formación de la } \\
\text { estructura psíquica. } \\
\text { - } \quad \text { Entre } 18 \text { meses y } 2 \text { años. } \\
\text { - } & \text { Etapa sensorio oral. } \\
\text { - } & \text { Resolución de la } \\
\text { Transición: Depende de la } \\
\text { estabilidad y continuidad } \\
\text { de atención de padres. } \\
\text { - } \quad \text { Se construye el "supo- yo" } \\
\text { sobre la base del "ello" y el } \\
\text { "yo": Se transmiten las } \\
\text { primeras reglas de } \\
\text { convivencia humana. } \\
\text { Educación: Consolida los } \\
\text { valores }\end{array}$ \\
\hline
\end{tabular}

\section{LA AUTOESTIMA, LOS VALORES}

\section{Y LA CALIDAD}

La cultura, la calidad y los valores son términos que entrañan elementos que los vinculan íntimamente con el comportamiento de las personas. A lo largo del presente artículo se viene demostrando que la calidad de las personas es consecuencia de su autoestima alta y la práctica constante de valores positivos. Son ingredientes claves que si no forman parte de una cultura es vital adoptarlos para un comportamiento personal y organizacional de calidad; por eso hay quienes creen que la calidad se 
ha transformado hoy en día en un valor muy preciado y buscado. Hábitos, costumbres, creencias, intereses, conocimientos, tradiciones, historia de una organización y todos sus valores son parte de una cultura, reflejadas en las formas de trabajar, vender, servir, negociar, interactuar con otras personas, solucionar conflictos y todo tipo de problemas. Aún cuando son realizadas por miembros de una organización de acuerdo con los paradigmas existentes dentro de ella, es posible hablar de un comportamiento organizacional, y así, de una personalidad organizacional.

Se puede despersonalizar a un trabajador o creer en un desdoblamiento de la personalidad, para que su actuación corresponda totalmente a la de la empresa o a la suya propia?, definitivamente no. Hay una suerte de complementación entre las conductas aprendidas dentro de la empresa y aquellas que lleva consigo mismo. De manera que un producto o un servicio de calidad es el resultado de un valor agregado sobre los modelos del sistema que transfiere el trabajador al intervenir en la ejecución de sus tareas. Schein (1992), llama a este fenómeno como valores adoptados, y los define como las "razones que esgrimimos para explicar porqué hacemos lo que hacemos". Estos valores se pueden encontrar en los fundadores de la cultura de la empresa. De este modo, la competitividad de la empresa y la calidad de los bienes o servicios estarían determinadas fundamentalmente por la calidad humana

Pero sería aún más saludable si todos los componentes de la empresa intervinieran con calidad. Insumos y materiales de calidad, herramientas y maquinaria de calidad, personas de calidad. Lograr que todos los elementos sean de calidad, excepto el hombre, no es tarea difícil, hacer ajustes a los procesos con relativo cuidado para la adquisición de dichos elementos, puede ser suficiente. En cambio lograr la calidad de sus trabajadores será producto de un esfuerzo minucioso, sistemático, largo, espinoso y muchas veces frustrante, pero no imposible.

La aspiración que tienen las organizaciones de una cultura de la más alta calidad para servir lo mejor posible a la sociedad de la cual forman parte, implica otorgar una posición preponderante y un tratamiento prioritario al desarrollo o cambio de la cultura organizacional y de todas sus implicancias humanas dentro de la organización. Los valores, como 
parte de tales implicancias sean éstos implícitos o tácitos, conscientes o inconscientes, constituyen la base de los objetivos organizacionales e individuales y también de las expectativas. Por otro lado, son la base ideológica del comportamiento humano para el cumplimiento de normas y de roles dentro de la organización, por eso se espera que exista congruencia de los valores organizacionales con los grupales e individuales (Porter, Lawler \& Haclanan, 1975).

Las organizaciones y/o profesionales dedicados a la consultoría para la implementación de la calidad consideran con mucha razón que no es posible competir sin calidad, que es necesario crear conciencia de calidad en todos los miembros de la organización, iniciándose en los niveles más altos, para luego descender a los trabajadores de los niveles más bajos que son los que están en contacto directo con el cliente o indirecto a través del bien que fabrican.

Los directivos y funcionarios que han experimentado este proceso consideran que la mejor forma de crear conciencia es a través del ejemplo. Los directivos de escritorio ya no pertenecen a esta época La mejor manera de enseñar es demostrando modelos de conducta, recorriendo desde lo más alto hacia lo más bajo de los niveles jerárquicos y desde el interior de la organización hacia las familias dentro de la sociedad a través de los trabajadores y los clientes. Otros en cambio creen que no es suficiente, que es necesario mediante la educación escolarizada y no escolarizada y proponen incorporar dentro de sus planes estratégicos e invierten ingentes sumas de dinero con fines de educación. Desde nuestro punto de vista, las dos propuestas no se contradicen, por el contrario, se complementan.

Los cambios de la cultura tradicional a nuevos patrones de desarrollo incluso los cambios de actitudes negativas hacia actitudes de desarrollodemandan de una dedicación sin límites; probablemente este rubro es mucho más alto en costo total que el propio entrenamiento para mejorar las habilidades. H. Kasuga (1992) nos dice al respecto que " ... empresa que no capacite a su personal sale de la competencia y trabajador que no se capacite sale abortado por el sistema ... " .En otro momento, ella misma destaca que " ... la calidad empieza con la educación y termina con la educación ....". 
Todos los componentes de la cultura son, sin duda, imprescindibles; sin embargo, son la autoestima y los valores que llevan consigo los miembros de una organización y los aprendidos dentro de ella, los que destacan por la vitalidad que infunde en las empresas a pesar de la crisis y la inseguridad. Luego, son los trabajadores los que en última instancia sostienen la calidad en el servicio o en la producción del bien. Es la autoestima de ellos la que les da energía, pasión, impulso a sus actos en todo terreno, especialmente en el trabajo y, son los valores los que regulan los extremos del comportamiento, los que determinan la rectitud de la conducta, de los objetivos, etc. Los valores nos protegen contra esos errores, son esenciales para lograr los objetivos. Así, la calidad resulta siendo el reflejo de los valores positivos y una auto estima suficiente y necesaria de los miembros de una organización.

\subsection{Los Secretos de la Calidad}

Hablar de los secretos de la calidad da pie a creer que los secretos son producto de una receta. No es tan fácil. Lograr la calidad humana, como parte de todos los secretos que pueden existir, sólo será posible a lo largo del desarrollo de la propia existencia del ser humano. En otras palabras, la presencia del elemento humano dentro de las organizaciones hace pensar que sólo un trabajo sostenido con ellos puede ser la clave de todas las calidades.

\section{a) Autoestima alta}

Todas las teorías psicológicas apuntan a relevar la autoestima como una etapa de vital importancia en el desarrollo del hombre para el logro del éxito en sus realizaciones cotidianas y futuras. En los acápites anteriores se ha tratado con algún detalle sobre cuándo, dónde y cómo aparece la autoestima. Aquí se está en condiciones de afirmar que la calidad humana depende mucho del grado de autoestima alcanzado por la persona en sus primeros años de existencia y las estimulaciones posteriores que la consoliden.

Efectivamente, de lo anterior se infiere, qué el trabajo duro, sistemático y sostenido está en nuestra infancia. El cambio de nuestra 
sociedad hacia una cultura de calidad tomaría tiempo. Estaríamos hablando por lo menos de 18 a 20 años mínimos. Entonces, ¿cuál es el papel que toca a las organizaciones hoy y ahora? Evidentemente, sentar las bases de una educación diferente y educar a los padres de familia en todos los centros de trabajo, parroquias, clubes, centros comunales y todas las instituciones donde quepa la posibilidad de reunir a los jóvenes y adultos de ahora

Lo más indicado es formar a las personas para que tengan una alta autoestima, dentro de ciertos límites, a fin de generar responsabilidad frente a los compromisos y cada uno de sus actos, honestidad y honradez frente a la confianza brindada, comprensión y amor consigo mismo y con los demás; cooperación, solidaridad y reciprocidad en sus interacciones sociales, e integración en el trabajo grupal.

Las personas con una autoestima alta confían plenamente en sus decisiones, en sus actos, no temen los retos del futuro y encuentran en cada barrera u obstáculo una posibilidad de aprendizaje y motivación para resurgir con mayores bríos; por eso, los conflictos y desequilibrios de su vida cotidiana, por difícil que esto fuera, son tomados y encarados con toda naturalidad. Se trata, pues, de una persona segura de sí misma, dispuesta a compartir su vida con los demás, su experiencia, sus virtudes y también a pedir ayuda sin temores porque confía en los demás con la misma fe que se tiene a sí misma.

Todo lo anterior parece asegurar un éxito absoluto en el futuro de una persona. No es así. Existen limitaciones físicas, mentales y del ambiente en el entorno de la persona que puede entorpecer el desarrollo normal de sus facultades; entonces, los esfuerzos por brindarle las mejores y mayores atenciones no tendrán los mismos resultados.

Es también una limitación el exceso en la estimulación de la autoestima en personas emocionalmente inmaduras. Esta limitación que nace fundamentalmente fuera de la persona y es mal interpretada, tal vez sea la más peligrosa por la especial habilidad que existe en este tipo de persona para ocultarla, y puede traer abajo todo el esfuerzo y la buena intención por ayudarlo de quienes la rodean; se trata de aquellas personas presumidas, petulantes, soberbias y arrogantes que terminan por arruinar su existencia frente a las bondades que ofrece el poder económico, político o social. 
Esto sucede generalmente en personas que han desarrollado una falsa autoestima, o han perdido su valía y su aprecio hacia sí misma, llegando hasta la deshumanización. En las personas que son poseedoras de una autoestima sólida funciona con naturalidad un reconocimiento y una aceptación sana de sus bondades para no llegar a la deshumanización por que ellas irradian confianza, expectativa y bondad.

Luego, las personas con una autoestima alta son capaces de liderar un grupo, una comunidad o una sociedad; crear nuevos métodos de trabajo. diseñar máquinas y herramientas, inventar formas de solucionar problemas que afectan a un grupo o a una comunidad o sociedad en general; innovar y emprender obras de gran valor presentes y futuras en el trabajo, en la organización, en el país o en una sociedad en favor de sus miembros, sin esperar nada en compensación por el esfuerzo desplegado.

\section{b) Valores trascendentales}

Los valores humanos básicos (moral, ética, respeto, honradez, verdad, disciplina, etc.) que nació en las escuelas para ser difundidas entre los niños y jóvenes, trascendió sus fronteras para involucrarse en los centros de trabajo. Tal vez los maestros no tuvieron siquiera idea de la trascendencia de sus enseñanzas o tal vez sí, pero en muchas sociedades latinoamericanas se perdió "la brújula" debido a la irresponsabilidad de los líderes políticos de escasa autoestima que no supieron apreciar las bondades de dichas enseñanzas, y sometieron a los maestros a maltratos constantes e interminables década tras década, haciendo perder su propia perspectiva y valía.

Estos valores que surgieron como trascendentes para la formación de niños y jóvenes en la escuela y que perdió su relevancia, son ahora de necesidad vital en las oficinas administrativas de cuanta organización exista en una comunidad y también en las plantas de las fábricas y comercios porque en ellas se sustenta el progreso social y económico de nuestras sociedades. La calidad de vida de una sociedad está sustentada precisamente en la calidad de sus recursos humanos más que en sus recursos naturales. Japón es un ejemplo de ésta afirmación.

Hoy en día todas las organizaciones ponen mucho énfasis en los valores como punto de partida de sus objetivos, y no es que los objetivos 
tengan su origen o procedan de los valores; si no que, como se dijo anteriormente, los valores regulan la conducta de las personas, de manera que orientarán la rectitud en el cumplimiento de dichos objetivos, porque éstos son trazados a partir de una percepción clara del futuro, generalmente de los fundadores de la empresa o de sus directivos más visibles.

La idea parece clarificarse cada vez más al acercarse a las organizaciones y preguntarse sobre el ¿porqué trascender? y ¿cuáles son aquellos valores que trascienden?; la respuesta está allí, presente y ahora, es el momento de la verdad -como dicen los vendedores. Cuando en una organización familiar el padre tiene que optar por ser un buen padre o un mal padre, está trazándose un objetivo. Si se trata de una persona con una autoestima alta y valores positivos, tendrá deseos de vender una imagen positiva con total confianza y logrará ser una persona reconocida, apreciada, amada y respetada por su manera de comportarse frente a su esposa, a sus hijos, a sus amigos, a sus compañeros de trabajo; luego, hay la probabilidad de que quienes le conocieron encuentren en él un modelo de conducta que vale la pena reproducir.

En las organizaciones empresariales ocurre exactamente lo mismo. La organización tiene objetivos, la conducta de los directivos están encaminados a cumplir cada uno de los objetivos; los trabajadores reproducen ese modelo y se encaminan juntos hacia dichos objetivos, ¿que les lleva a alcanzar ese objetivo sin vacilaciones y sin distorsiones?, precisamente son los valores los que conducen con esos actos, no sólo a lograr objetivos previamente percibidos sino también a trascender más allá de la propia empresa. Gracias a los valores positivos de sus miembros, a la rectitud con que actuaron y a la coherencia de los mismos la empresa es lo que merece ser.

Mauro Rodríguez Estrada y cols. (1993) expresan esta analogía de la siguiente manera:

La, empresa es una persona moral: al igual. que las personas físicas, necesita clarificación de valores. Al igual que las personas físicas tienen zonas claras de plena conciencia y zonas oscuras de subconsciencia; y al igual que ellas, tiene necesidades que buscan como cauce una espiral muy abierta, con valores cada vez más altos, más amplios y más ambiciosos: 
diríamos que no es una rueda que gira, ni siquiera una espiral plana, sino una espiral de tres dimensiones, una línea giratoria y ascendente.

Todos los valores tienen condiciones para trascender a las personas $\mathrm{u}$ organizaciones si tienen una alta autoestima que les permita forjar una escala de valores positivos, o al revés, valores positivos que retroalimenten o refuercen su autoestima. Algunos de estos valores podrían ser:

$\begin{array}{llll}\text { la confianza } & \text { la limpieza } & \text { la honestidad } & \text { el éxito } \\ \text { la alegría } & \text { la disciplina } & \text { el progreso } & \text { la armonía } \\ \text { la seguridad } & \text { la amistad } & \text { la sabiduría } & \text { la honradez } \\ \text { el respeto } & \text { el ahorro } & \text { la austeridad } & \text { la lealtad } \\ \text { la perfección } & \text { la eficiencia } & \text { la responsabilidad } & \text { la productividad } \\ \text { el servicio } & \text { la creatividad } & \text { la patria } & \text { la moralidad } \\ \text { la educación } & \text { el orden } & \text { la flexibilidad } & \text { la unidad } \\ \text { la cortesía } & \text { la dignidad } & \text { la comunicación } & \text { la sinceridad } \\ \text { la puntualidad } & \text { la iniciativa } & \text { la tenacidad } & \text { el prestigio }\end{array}$

De manera que la autoestima como los valores tienen trascendental importancia en la incubación de la calidad humana Cuanto mayor sea el grado de autoestima en la persona, mayor será la internalización de valores positivos como parte de sí que generen conductas de calidad. Igualmente, cuanto mayor sea la cantidad de valores positivos en la persona la autoestima se verá retroalimentada para generar conductas de calidad. En otros términos, hay un proceso de interacción permanente y mutua entre la autoestima y los valores. Por eso se puede afirmar que los secretos de la calidad del hombre como los de la organización se encuentran en la autoestima y los valores que se generen.

Así, los valores al igual que la autoestima aparecen interdependientes con la calidad humana, de suerte que si los recursos, tanto humanos como materiales de la empresa son de calidad sí estaría asegurando una cultura organizacional de calidad y por ende los servicios que brindan o los bienes que producen. Ello no significa interdependencia de recursos. Significa que los recursos materiales (insumos, materiales, herramientas, maquinaria) son producto de la 'mano del hombre y de su calidad como ser humano. Por tanto, está bajo su control fabricar lo mejor posible y usarlo de la mejor manera en beneficio de la humanidad. 


\subsection{Las Barreras del Éxito}

La existencia de autoestima alta y valores positivos en las personas hacen suponer la existencia de autoestima baja y valores negativos que engendran conductas igualmente negativas, tales como las conductas antisociales en el sentido más amplio de la palabra.

\section{a) Autoestima baja.}

El mundo está habitado por seres humanos diferentes unos de otros y la individualidad es una característica esencial de su naturaleza; de modo que, esperar que todos sean regulares, buenos o excelentes es aún una utopía y seguirá siéndolo siempre por más esfuerzo que se haga por cambiar ese estado de cosas.

La autoestima es un continuo de grados que va de un polo a otro y en ése espacio cabe un conjunto de posibilidades de ubicación. Que las personas tengan como meta acercarse lo más posible a los niveles más altos es ver el mundo con altruismo. Lograr que un alto porcentaje de la población del planeta alcance un nivel de autoestima que vaya del 5 al 10 , en una escala que va del 1 al 10, sería lo más fabuloso que podría ocurrirle a la humanidad. Pero para infortunio de la humanidad un alto porcentaje de la población mundial está por debajo del promedio con todas las consecuencias que ello significa.

El escritor cubano, Salvador Mendieta, muchas décadas atrás (1912) decía que la suerte de América Latina estaba echada, desde que fue conquistada por los españoles en un momento en que la cultura de ése país estaba altamente influida por la religión católica que santificaba la vagancia, la fe sustituía la curiosidad intelectual, el trabajo era considerado como una maldición. La calidad y la excelencia son producto de valores totalmente contrarios a estos valores (L. Harrison, 1995). España ahora está cambiando mientras que Perú aún sigue igual si no peor."Si España está cambiando, el Perú también puede lograrlo. Es cuestión de decisión, del esfuerzo que hay que imponerse y del tiempo que toma la maduración de estos cambios.

Mantenerse en el estado en que se encuentra el Perú, ser pesimista o caminar a un ritmo muy lento frente a la globalización de la economía y 
de la cultura, sin elevar su competitividad en el mercado nacional y mucho menos en el mercado internacional es permanecer aislado de la realidad presente en que vive el mundo, esperando un milagro divino que le solucione sus problemas o la caída definitiva que le lleve a cerrar sus puertas.

Lo anterior es, precisamente, propia de las personas con una autoestima baja, que no hacen nada o hacen poco para salir a flote, sumiéndose en la soledad y la desconfianza. Lamenta sus errores y espera toda clase de desprecio de quienes lo rodean; entre tanto se hacen cada vez más indiferentes y apáticos consigo mismo y con los demás y si actúan procuran proyectar su propio desprecio y agreden de palabra y a veces de hecho a quienes están cerca a ellos, dentro de una barrera de temores incontenibles y permanentes que le impide a buscar alternativas que lleven a solucionar sus problemas.

Las características más comunes de las personas que se aprecian poco es el aislamiento del mundo externo, los sentimientos de inferioridad frente a los demás, la inseguridad y el temor que los hace inactivo para encarar sus dificultades y la posibilidad de caer en una profunda depresión que termine con el suicidio o el homicidio; pero de sobrevivir esta situación están llenos de rencor, de celos, de agresión y egoísmo que son capaces de atentar contra la felicidad de otros.

En las organizaciones las personas con baja autoestima son incapaces de reconocer las bondades del otro porque están llenos de envidia, pensando siempre de sacar ventaja del compañero o de la empresa. Su trabajo es más un obstáculo que una oportunidad de realización y satisfacción, no hay una entrega total de su ser y sus sentimientos a la labor que ellos realizan; es más, son expresivos en su manera de vender, de conversar con el cliente, de manipular los productos que fabrica con desperdicios y errores sin reparar en los perjuicios al cliente y/o a la empresa Su indiferencia, su inseguridad, su apatía, sus temores y agresividad se traslucen en sus gestos, en sus movimientos, en sus actitudes, en su comportamiento, perfilando un clima negativo en el ambiente laboral. Es más, se sienten amenazados y proyectan toda su manera de ser hacia sus propios compañeros.

Por consiguiente, una autoestima baja en un trabajador, producto de su propia formación, o producto del mal trato sistemático y permanente 


\section{Alejandro Loli / Ernestina López}

dentro de la propia empresa (hostilizaciones, humillaciones, falta de respeto, bromas del mal gusto, etc.), deteriorando su autoestima, rebajándole en su amor propio, en su orgullo y en su dignidad como ser humano, llevándole a dudar hasta de su propia existencia tal cual es, sólo produce resultados negativos en lugar de beneficios, constituyéndose en una de las barreras menos visibles, pero más perjudiciales y más difíciles de solucionar, al igual que los valores negativos, que ningún otro segmento de la organización.

\section{b) Los valores negativos}

Tomas R. Friol, en un trabajo sobre "Factores sociales del desarrollo económico" publicado en 1960, decía que " ... el perfil de orientación de valores pasivo, apático, indiferente, es un factor crítico que limita las posibilidades de desarrollo económico ... " de un país y el cambio cultural.

Al igual que en la autoestima, existen en los valores una escala que distingue entre lo que es más importante y lo que no lo es. Cada persona construye sus valores sobre la base de la autoestima lograda en la familia y luego en las personas influyentes en el núcleo familiar (p.e. el párroco del barrio, el médico de cabecera o el psicólogo de la familia), son ellos los que señalan las normas de qué hacer, qué decir, cómo actuar, cómo comportarse, etc. en una u otra situación. Hay un proceso de aprendizaje y práctica de dichos mensajes hasta que se convierte en parte de sí.

Una segunda fuente o cantera de valores que le permite enriquecer o deteriorar los aprendidos en el hogar es el sistema cultural dominante que le rodea, tales como amigos, colegas, maestros, jefes, compañeros de trabajo y la sociedad en su conjunto mediante la transmisión de valores implícitos o explícitos.

Una tercera fuente de influencia vendría a ser la presencia de todas aquellas culturas foráneas a él que la radio, la televisión, la computadora (Internet), las revistas, los periódicos, y todos los medios de comunicación masiva reproducen y conducen al hogar sin consentimiento de nadie, sin tener acceso a la toma de decisiones de parte de la familia, mucho menos de los niños -se llega a extremos de agredir la cultura y los valores espirituales inculcados en el hogar a través de la 
transmisión publicitaria de programas de sexo y violencia, vetados para cierta edad, junto a programas infantiles- ¿Se puede esperar una juventud sana, de valores positivos con modelos de esta naturaleza?, ¿de qué nos quejamos cuando los propios medios de comunicación que la difunden nos hacen saber horrorizados de niños violados y agredidos por .los adultos o jóvenes mayores?, ¿no es acaso obligación del Estado regular este tipo de excesos para proteger el desarrollo de sus ciudadanos? La calidad y la excelencia son producto precisamente de valores totalmente contrarios a los promovidos por esta fuente.

Existen valores dentro de la diversidad de culturas que son rescatables para solucionar los problemas existentes de otra sociedad. De eso se trata, si no logramos clarificar nuevos valores como personas, y seleccionamos en el debido orden de importancia dichos valores para construir nuestro sistema de valores de acuerdo a las necesidades, menos podrá lograrlo una organización y, si lo logra a pesar de todo, se tendrá que enfrentar a un grupo humano sin identidad de valores, que es lo mismo que tener valores negativos. Entonces, será cotidiano ver gente indisciplinada, sin objetivos, desordenada, floja, sucia, irresponsable, irrespetuosa, desobediente, sin creatividad ni iniciativa; incapaces de sostener una comunicación sana, de hacer una amistad franca y leal, el chisme y la zancadilla será su mejor arma de interacción humana La cooperación, la reciprocidad y la solidaridad brillan por su ausencia Estos valores que se reproducen en armonía con los grados de autoestima alcanzados -son propios de personas con una autoestima baja- no son los valores de progreso, de desarrollo, de calidad que una empresa requiere para entrar a un mundo de competitividad que el mercado actual exige. Son valores que conducen o mantienen a una persona, a un grupo, a una empresa o una sociedad en la postración, postergando décadas tras décadas las aspiraciones de tener un mejor nivel de vida. Con mucha razón, A. Maslow (1971), decía que " .. .la más honda enfermedad de nuestro tiempo es la falta de valores" (en M. Rodríguez, 1993).

Como es lógico esperar después de lo anterior, las personas que actúan así son aquellas que tienen una autoestima baja, y probablemente sean de las que no tienen una autovaloración ni una autoimagen favorable de sí mismos; en el mejor de casos, deben tener su escala de 
valores distorsionada; por ejemplo, para el delincuente el hurtar es equivalente a trabajar; para el funcionario corrupto el trabajo honesto, leal, ordenado es una barrera a sus actos de libre albedrío; para un empleado ocioso el trabajo es un castigo divino.

\section{LA EXCELENCIA DE LAS ORGANIZACIONES}

Hasta aquí se ha tratado de explicar la naturaleza de la autoestima de las personas, de los valores humanos y la influencia de éstos en el logro de la calidad, primero humana y luego del producto y del servicio. Ahora se sabe que no es posible la calidad del servicio ni del producto sin la calidad humana, pero tampoco es posible la calidad humana sin una construcción de la autoestima y los valores a los niveles más altos.

La excelencia es un valor todavía abstracto, y los teóricos siguen discutiendo sobre los límites y alcances, lo que se sabe es que la excelencia califica la calidad superior, la grandeza extraordinaria de otros valores; implica superioridad, perfección. Ser distinto y destacado de entre otros. Por lo mismo, es el valor más buscado y preciado por muchos.

Existen autores que consideran que la excelencia es un valor de las organizaciones más que de las personas, porque según ellos la excelencia lleva en sí la idea de comparación y ésta es propia de las empresas. Aún así, de la excelencia de la persona o de la empresa, ¿cuál es el momento en que deja -se supone el grado más alto- de ser calidad para pasar al mundo aún desconocido de la excelencia?

M. Rodríguez y cols. (1993) refieren acerca de la investigación realizada por Thomas J. Peters y Robert H. Waterman en 43 empresas más brillantes de los Estados Unidos y que fue publicado en 1982, encontrando ocho factores clave del éxito y grandeza de estas empresas:

- Habitual disposición a la acción; en vez de empantanarse en análisis interminables y en estudios de comités.

- Contacto cercano y activo con la clientela; captando sus necesidades y gustos, y dialogando siempre con este público.

- Cierta autonomía de los departamentos, que los hace sentir como pequeñas empresas dentro de la empresa y los estimula a pensar y actuar creativamente. 
- Productividad a través de la gente, inculcando a todos los empleados la conciencia y la convicción de que su trabajo es muy importante, y que ellos participan y participarán del éxito de la compañía.

- Valores claros y muy bien asimilados; con definida caracterización de algunos valores esenciales para la compañía.

- $\quad$ Fidelidad a la propia línea; permaneciendo en los negocios en que la compañía tiene experiencia y competencia.

- Sencillez organizativa; el organismo tiene pocos niveles; los estrictamente necesarios.

- Conjugación de propiedades "flojas" y "apretadas"; es decir, un clima de gran entrega a los valores esenciales de la compañía y de flexibilidad y tolerancia en todo lo demás.

En estas ocho variables del éxito empresarial se observa seis variables de contenido esencialmente humanos, y todos ellos tienen que ver con los valores, lo que permite deducir que la clave del éxito empresarial de la calidad, viene a ser la autoestima como generadora de valores y los valores como reguladora de la conducta de los recursos humanos. ¿Pero serán éstos los tipos de empresa a las que podemos llamar de excelencia?

L. Harrison (1995) en una conferencia dictada en la Sociedad Nacional de Industrias, sobre Actitudes y valores para la calidad, hacía una comparación entre el Japón y el Perú, señalado que:

Mientras que en Perú sólo el 15\% de adultos son alfabetos, en el Japón el 100\% de los adultos son alfabetos. La esperanza de vida en Perú es de 64 años, en Japón es de 79 años. Mientras que en Perú la democracia es aún un infante, en Japón la democracia es una realidad sólida. El Perú es un país rico en recursos naturales, mientras que Japón es un país pobre en recursos naturales. Sin embargo, Japón es uno de los países económicamente más poderosos del planeta, mientras que Perú es un país económicamente más pobre, con un nivel de vida más bajo del planeta.

¿Qué explicación cabe, a esta ilustración tan evidente y significativa?

La única explicación razonable parece estar en el crecimiento psicológico de sus recursos humanos; es decir; Japón es un país que ha puesto todo su esfuerzo en educar a su sociedad y desarrollar' valores humanos positivos de toda esa sociedad. Lo que el Perú carece y lo que los líderes políticos aún no alcanzan a comprender es que los niños en cualquier 
país del mundo nacen iguales, "limpios y puros", potencialmente dispuestos a toda influencia y esperando una oportunidad para aprender valores y actitudes de progreso y de calidad durante su crianza y su educación. Ya decía Frornm, algunas décadas atrás, que es posible que un niño sea lo que uno quiera que sea.

Las caídas que muchas veces se experimentan en el curso de la vida son formas de aprendizaje naturales que deben ser tomadas como un reto a ser vencidas. Las empresas como las personas tienen la capacidad de levantarse una y otra vez; como dice M. Rodríguez, marchar " ... hacia el éxito y la excelencia, reconciliándose consigo misma después de cada tropiezo", es sólo de las personas u organizaciones con alta autoestima y valores positivos.

En esta misión, podría decirse tal vez que las organizaciones de excelencia son aquellas que, teniendo las condiciones humanas y tecnológicas tienen éxito, se mantienen y día tras día, se superan y crecen juntos: empresamiembros-clientes; mientras que otras con las mismas condiciones no logran los mismos niveles. No podría ser de otra manera, los clientes son los que en última instancia sabrán calificar el grado de calidad o excelencia alcanzados por las empresas en concordancia con su satisfacción o insatisfacción, gracias a la confiabilidad del servicio o producto.

Si requiero un gasfitero y éste me recibe con mucha gentileza pero como técnico es un desastre, prefiero a aquel otro que no es tan amable pero que me soluciona los problemas de agua o desagüe tan molestosos en la casa.. Se trata, pues, de algo que va más allá de la amabilidad y la cortesía, aún cuando estos sean indispensables. Así visto, excelencia es un objetivo que toda empresa de calidad se propone para responder a las demandas de un grupo seleccionado de clientes.

Parece ser que aquí está la clave que permite distinguir la calidad de la excelencia Mientras que calidad es cumplir con los requerimientos del cliente a satisfacción, excelencia es ir más allá de la satisfacción, es abarcar las expectativas. El cliente está permanentemente valorando a sus productos o proveedores y está observando lo que está haciendo más allá de las formalidades rutinarias, es decir, ¿cuál es el valor agregado de su producto o servicio para mantenerlo o mejorarla?. Estos añadidos pueden ser muchas: rapidez en las entregas o fabricación en el tiempo previsto, 
preocupación notoria por sus clientes (por ejemplo, visitas al cliente para evaluar el servicio), solución de problemas excepcionales, ayudar a solucionar los problemas del cliente (por ejemplo, una empresa de vigilancia que brinda apoyo de primeros auxilios en situaciones de emergencia), proporcionar apoyo postventa (por ejemplo, soporte técnico: repuestos, reparaciones, actualizaciones, etc.).

J. Horovitz (1996), nos dice que la " ... tentación de satisfacer a todos un poco ha pasado a ser el medio más seguro de fracasar". Este mensaje tiene mucho sentido, en la medida en que la empresa cuente con muchos clientes que le lleve a discriminar entre clientes más importantes y menos importantes o más grandes y menos grandes, situación en los que los clientes chicos y menos importantes no reciben la excelencia del servicio brindado a los clientes más importantes; con lo que su imagen se irá deteriorando, el respeto ganado se irá perdiendo, sus valores se irán estrechando y reduciendo a una simple búsqueda del lucro económico. Para una empresa de excelencia no hay clientes chicos ni grandes, como tampoco existen clientes más importantes o menos importantes. Una empresa de calidad que tiene como objetivo la excelencia es aquella que valora por igual a todos sus clientes y busca progresar junto con ellos. El valor agregado hace a las empresas, de una manera u otra, empresas de excelencia No se debe olvidar que cuando los precios son iguales, el cliente opta por aquel que es de mayor calidad; cuando dos productos son de igual calidad, el cliente opta por el más barato. Lo ideal sería, a igual calidad de producto o servicio, igual precio. Este es la tendencia de las empresas de excelencia.

\section{CONCLUSIONES}

a) La autoestima genera valores positivos si durante el desarrollo de la persona y su adaptación al medio se le presta las atenciones suficientes y necesarias para mantener alta su autoestima.

b) Los valores regulan y orientan la rectitud de las actitudes y el comportamiento humano.

c) La autoestima alta y los valores positivos generan personas de calidad en sus interacciones personales y sociales. 
d) Las personas de calidad generan productos y servicios de calidad en las organizaciones.

e) La sociedad latinoamericana y peruana son comprometerse en este proceso de cambio, a tropiezos culturales de su historia

f) La excelencia es la extrema perfección de la calidad y aún los teóricos discuten sobre las limitaciones y alcances.

g) La llave del éxito y la calidad personal y organizacional se encuentra básicamente en la autoestima y no en los valores. Un trabajo para el cambio de valores sin tomar en cuenta la autoestima es inconsistente e incoherente en el tiempo. Por tanto, es necesario trabajar, con las familias a fin de inculcarles la necesidad de un desarrollo sostenido durante la formación de la autoestima (basta los 18 meses) y la generación de valores iniciales que sirvan de base y sostén a los siguientes.

\section{BIBLIOGRAFIA}

Alcantara, J. A. (1993). Cómo educar la autoestima. Barcelona:CEAC.

Allport, G. W. (1968). La personalidad. Barcelona: Herder.

Barry, T. J. (1996). La excelencia como hábito. México: Panorama.

Cela, J. L. (1996). Calidad: ¿ Qué es, cómo hacerla? Barcelona: Gestión 2000.

Harrison, L. (s/f.). Valores y actitudes para la calidad. Lima: SNI.

Horovitz, J. (1996). La calidad del servicio. Madrid: McGraw-Hill Interamericana.

Ismodes, A. (1965). Sociología. Lima: BSPS.

Kretch, D. (1972). Psicologia social. Madrid: Biblioteca Nueva.

Levow, R. (1995). La clave de la productividad empresarial. México.

Loli, A. (1989). La confianza interpersonal en las cooperativas del Perú. Lima:Tesis Doctoral, U.N.M.S.M.

Lopez, J. y cols. (1996). La excelencia trascendente de la empresa; México: Panorama. Marguilies, N. y Raia, A. (1986). Desarrollo Organizacional: Valores, Proceso y Tecnologla. México: Diana Montgómery, W. (1997). Asertividad, autoestima y solución de conflictos interpersonales.

Lima: CEA.

Mora, G. (1995). Valores humanos y actitudes positivas. Bogotá: McGaw-Hill lnteramericana. Munch, L. (1996). Más allá de la excelencia y de la calidad total; México: Trillas.

Peiró, J.M. (1983). Psicología de la organización. Madrid: Universidad Nacional de Educación a Distancia.

Peters, T. J. \& Waterman, R.H. (1996). En busca de la excelencia. Bogotá: Norma. 


\section{Autoestima y Valores}

Rodriguez, M. (1993). Los valores, clave de la excelencia. México: McGraw-Hill Interamericana. (s/f). Cómo desarrollar la autoestima. México: Centro de Asesoría y capacitación.

Rogers, C. (1979). Psicoterapia centrada en el cliente. Buenos Aires: Paidós.

Torres, E. y co15. (1995). Desarrollo de la autoestima. Lima: B.F.Skinner.

Vicuña, L. (1997). La motivación de logro y el autoconcepto en estudiantes universitarios de la U.N.M.S.M. En: Instituto de Investigaciones Psicológicas, Investigación en Psicología: Retos Para el Futuro. Lima: IPSI. 
